\title{
Urban boundary extraction and sprawl analysis using Landsat images: A case study in Wuhan, China
}

\author{
Shougeng $\mathrm{Hu}^{\mathrm{a}, \mathrm{b},{ }^{*}, 1}$, Luyi Tong ${ }^{\mathrm{a}, 1}$, Amy E. Frazier ${ }^{\mathrm{c}}$, Yansui Liu ${ }^{\mathrm{b}}$ \\ a Department of Land Resources Management, China University of Geosciences (CUG), Wuhan 430074, China \\ ${ }^{\mathrm{b}}$ Institute of Geographic Sciences and Natural Resources Research, Chinese Academy of Sciences, Beijing 100101, China

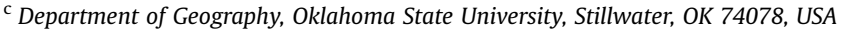

\section{A R T I C L E I N F O}

\section{Article history:}

Available online 13 February 2015

\section{Keywords:}

Urban sprawl

Urban boundaries

Land-use information entropy model

China's neo-urbanization

Landsat images

Landscape metrics

\begin{abstract}
A B S T R A C T
Periodic monitoring and multi-scale characterization of urban sprawl is essential for improving urban planning and development. However, historical sprawl analysis is not well suited for the neourbanization occurring in most cities in China due to the limited data available. This paper proposes a concise and cost-effective method for automating the extraction of urban boundaries (UBs). The method uses integrated land-use information entropy (LUIE) model along with ordinary Kriging based on a gridded land-use map derived from Landsat imagery to extract UBs. Results indicate that overall extraction accuracies greater than $90 \%$ were obtained using an 800 m-resolution LUIE combined with Kriging. The method was applied to identify UBs in Wuhan, China during 1987-2010, and the UBs were characterized at multiple scales and analyzed using landscape metrics. Results show varied landscape dynamics at local administrative and city scales. The study demonstrates that the method for UB identification and multi-scale analysis has the potential to contribute to sprawl monitoring and measurement at multiple spatial scales. Moreover, the findings from this study can potentially guide policy makers and urban planners tasked with understanding and controlling development occurring under neo-urbanization strategies in China.
\end{abstract}

๑) 2015 Elsevier Ltd. All rights reserved.

\section{Introduction}

Urbanization as a vital human-environment interaction has become a momentous force impacting regional and global sustainability. Numerous cities and metropolitan areas across the world have witnessed rapid urbanization characterized by disorderly urban sprawl, rapid population growth, and persistent economic improvements since the 1960s (Amiri, Weng, Alimohammadi, \& Alavipanah, 2009; Arribas-Bel, Nijkamp, \& Scholten, 2011; United Nations, 2012). In particular, urban sprawl characterized by unsustainable land-uses and imbalanced land cover dynamics has profoundly impacted urban-rural habitats, local biodiversity, hydrologic networks, and regional climate (Bhatta, Saraswati, \& Bandyopadhyay, 2010; Haregeweyn, Fikadu,

\footnotetext{
* Corresponding author. Department of Land Resources Management, China University of Geosciences (CUG), Wuhan 430074, China. Tel./fax: +86 2767883088.

E-mail addresses: husg2009@gmail.com (S. Hu), lytongc@gmail.com (L. Tong), amy.frazier@gmail.com (A.E. Frazier), liuys@igsnrr.ac.cn (Y. Liu).

1 These authors contributed equally to this work and should be considered co-first authors.
}

Tsunekawa, Tsubo, \& Meshesha, 2012), among others. Furthermore, intensive sprawl is predicted to continue, particularly in developing countries (Cohen, 2006; Mulligan, 2013). Curbing excess sprawl and working toward sustainable planning strategies have become the focus of both scholars and urban planners (Elmqvist et al., 2013).

Neo-urbanization, which is the transformation of historically rural and impoverished areas into developed cities, has been facilitated by China in the recent years. As the most populous developing country, China has been experiencing unfaltering economic and social strides since the 1980s, and the national urban population has increased from 0.14 billion to 0.71 billion over the period 1970-2012 (National Bureau of Statistics, 2013). Fostered by increasing consumption and investment, the per capita Gross Domestic Product (GDP) rose to 38,325 RMB Yuan in 2012, almost a one hundred-fold increase over the per capita GDP in 1970. Moreover, public services including education, healthcare, and transportation have greatly improved (Knight, 2013). Consequently, to accommodate the demand for urban land to sustain these activities, chronic disorderly sprawl has been occurring nationwide (Hubacek, Guan, Barrett, \& Wiedmann, 2009; Oizumi, 2011; 
Taubenböck et al., 2014). As a result of poor planning, many cities have suffered from massive traffic jams, steep rises in home prices, and ecological issues such as water pollution and atmospheric haze (Dhakal, 2009; Hu, Chen, Wang, \& Xu, 2013; Siciliano, 2012). Carrying out successful neo-urbanization strategies that focus on curbing accelerated urban expansion, fostering the agglomeration of urban, suburban and rural regions, and promoting a habitable environment is extraordinarily important for achieving sustainability (CDRF, 2013). However, effective strategies for sustainable urban growth have not yet been achieved despite the fact that China's central and local governments are endeavoring to curb excess expansion and shape land-use transitions using policy instruments (Bai, Shi, \& Liu, 2014).

One of main reasons that China has not been able to implement effective strategies for sustainable growth is because it has been difficult to identify and explain the intrinsic forces driving sprawl at multiple scales (Hersperger, Franscini, \& Kübler, 2014; Kane, Tuccillo, York, Gentile, \& Ouyang, 2014). This challenge has inspired researchers to strengthen analyses on the history and drivers of urban sprawl. The first step in this quest is to identify the urban boundaries (UBs), which constitute the bona fide boundaries between urban lands and all other non-urban areas (Han, Lai, Dang, Tian, \& Wu, 2009). With rapidly changing urban landscapes, methods for frequent and accurate UB extraction are urgently needed. Additionally, these methods are also extremely useful for regular sprawl monitoring and sustainable land use management, especially in China where most cities do not have historical UB data (Chen, Liu, \& Tao, 2013).

In recent years, remote sensing has become a viable method for identifying UBs (Tannier \& Thomas, 2013). Since the launch of Landsat 5 in 1984, the Landsat program has provided a continuous set of near-time surface reflectance data at a relatively low cost (Patino \& Duque, 2013), and the program is anticipated to continue for many years supported by the recent launch of Landsat 8 . The availability of archived historical imagery makes it possible to extract UBs over a prolonged temporal period and monitor areas across large scales.

Theoretically, UBs can be extracted from remotely sensed imagery as soon as the degree of urban development reaches a size that it can be identified at the resolution of the image. Land-use classification is an appropriate and universal method for identifying UBs since urban areas are usually comprised of artificial structures such as residential, commercial, industrial buildings, as well as spectrally different natural areas including green space and water (Weber, 2001). Methods such as artificial neural networks, expert systems, vegetation-impervious surface-soil (VIS) classifications, and support vector machines have been widely applied in urban land-use classifications (Foody, 2000; Pacifici, Chini, \& Emery, 2009; Pal \& Foody, 2010). Nonetheless, the resolution of the imagery and the heterogeneity characteristic of urban landscapes make it difficult to automatically map detailed urban lands solely using optical remote sensing methods (Cockx, Voorde, \& Canters, 2014). The use of ancillary datasets such as census data, road networks, impervious surface coverages, landscape metrics, land parcel attributes, and radar data were recently documented to improve urban classifications (Abed \& Kaysi, 2003; Berger et al., 2013; Chaudhry \& Mackaness, 2008; Hermosilla, PalomarVázquez, Balaguer-Beser, Balsa-Barreiro, \& Ruiz, 2014; Hu \& Wang, 2013; Schneider, Friedl, \& Potere, 2014; Soergel, 2010; Wu, Qiu, Usery, \& Wang, 2009). Fractal methods have also been documented as a successful component in aiding in locating UBs (Tannier \& Thomas, 2013; Tannier, Thomas, Vuidel, \& Frankhauser, 2011). However, ancillary datasets such as the ones described above as well as high-resolution imagery are costly and are seldom available for multiple areas across time and space. In terms of using intelligent algorithms, they are usually time-consuming and computationally expensive (Richards, 2013), and the contemporary frameworks are unrealistic when extrapolating UB identification to regional scales. Indeed, it is becoming more and more difficult to define and identify urban areas with the rapid pace of urban sprawl (Hollis, 2013; Rocchini et al., 2012; Weber \& Puissant, 2003). Straightforward methods for automated UB extraction from remote sensing images without the use of ancillary datasets are needed.

This work aims to develop a simple method for UB extraction using Landsat images and use this method to analyze the diverse effects of urban growth at multiple scales for landscapes in China. The paper first introduces the study area and image processing techniques followed by a detailed description of the methodological framework for extracting UBs. Assessment of the UB identification method and the findings from the multi-scale sprawl analyses are reported in the Results section. The effectiveness of the proposed method for UB extraction and the concept of multi-scale sprawl analyses are discussed, and conclusions for potential applications derived from this work are provided in the final section.

\section{Study area and image processing}

Wuhan, the capital of Hubei province, is located in central China near the middle reaches of the Yangtze River. It comprises a downtown and six suburbs covering a total area of $8495 \mathrm{~km}^{2}$ (Fig. 1). The landscape is primarily plains (39.3\%), water (26.1\%), and mountains (18.2\%). The majority of plains except for in the urban extents are used for agriculture. The downtown is divided into three parts (Hankou, Hanyang, and Wuchang) by the Yangtze and Han Rivers. Wuchang is the provincial education and administrative center. Hankou is where the regional commercial, financial and local administrative district is located, and Hanyang is the industrial center. With the Yangtze and Han Rivers as well as the BeijingGuangzhou Railway (BGR), Wuhan has become the transportation hub of China generating increasing social and economic growth (Cheng, Turkstra, Peng, Du, \& Ho, 2006; Wuhan Municipal Statistics Bureau, 2013). As such, Wuhan has experienced accelerated urbanization since 1987 and has benefited from land transaction and economic reform policies. However, unceasing migration, construction, and economic growth have spurred unmitigated sprawl, which is threatening local social and ecological stability (Du, Ottens, \& Sliuzas, 2010). Also, due to the dramatic economic and social development in downtown, urban-rural/suburban social gaps are observed. Therefore, the government and planners are now trying to reconfigure the city boundary expansion process and uncover its driving forces in order to moderate the rapid expansion and promote integrated urban-rural planning.

Multi-temporal Landsat (TM/ETM+) images taken from the US Geological Survey were adopted for deriving land-use information in the study (Table 1). Landsat ETM+ images taken during 2010, after the scan line corrector failed, were repaired with a selfadaptive local regression model (Lin \& Bao, 2005). Preprocessing including geometric, atmospheric, and radiometric correction as well as mosaicking was performed using ENVI 4.8. Land-use datasets of Hankou, Dongxihu, Hannan, and Huangpi, provided by the Hubei Province Department of Land Resources (DLRH) were used to assess the UB extraction method.

Maximum likelihood classification (MLC) was employed for land-use classification. For generating a relatively high-quality classification, a Principal Component Rotation (PCR) and local statistics were used in the MLC as they have been shown to improve MLC results (Deng, Wang, Deng, \& Qi, 2008; Ghinire, Rogan, \& Miller, 2010). Specifically, the first three principal components of the original Landsat bands (with an accumulated variance of almost 0.9) were determined using PCR. Next, the Getis-Ord $G_{i}$ index (Getis 

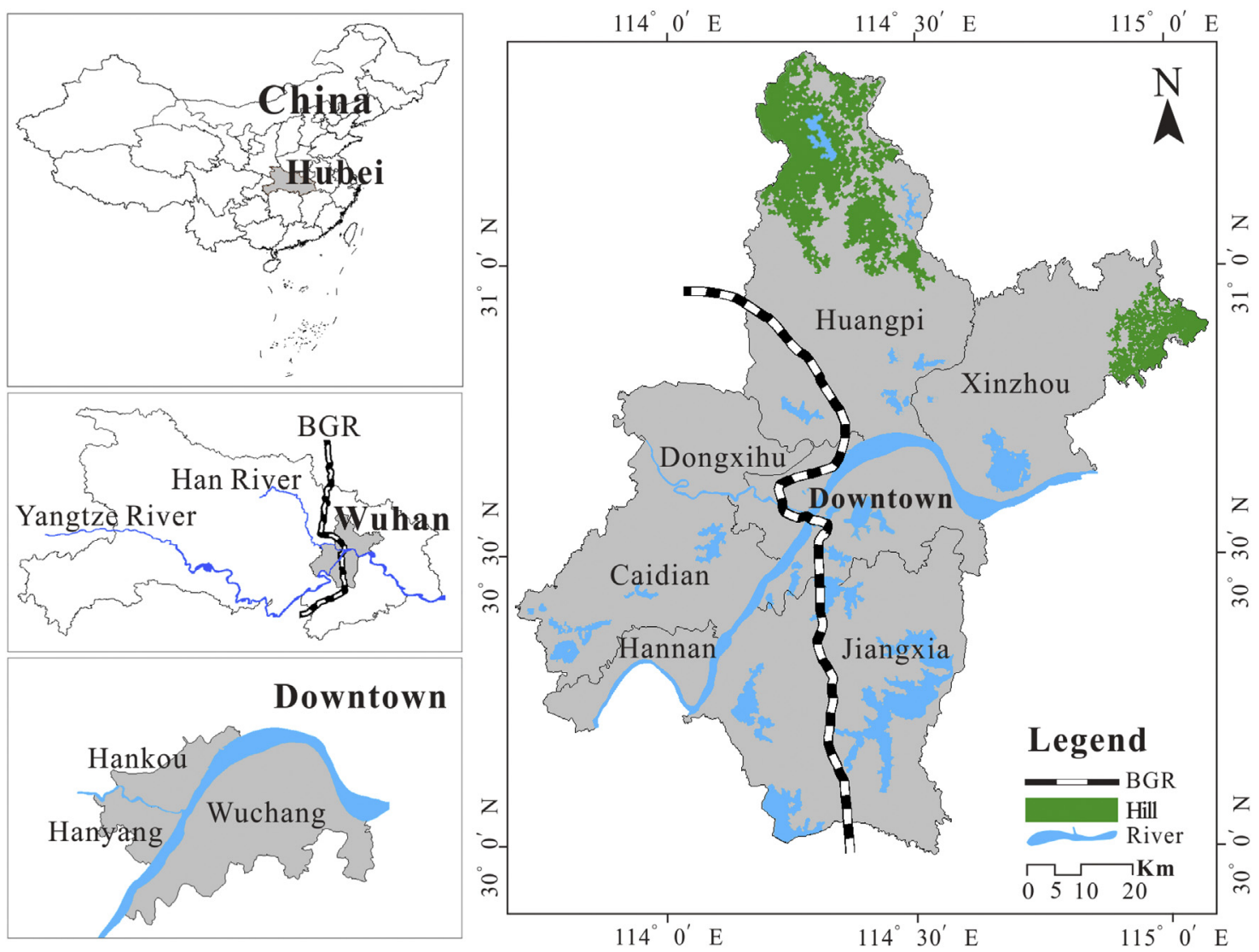

Fig. 1. Location of study area in Wuhan, China. BGR is the Beijing-Guangzhou Railway.

\& Ord, 1992) was computed for each component using rook connectivity with varying spatial lags from 1 to 6 . The $G_{i}$ statistic is a local spatial statistic that measures the concentration of a certain variable and therefore can be used to indicate local high and low clustering within the study area. The optimal lag for the $G_{i}$ index is determined by testing through the MLC results. Ultimately, four land-use classes, impervious areas, water, vegetation, and others (Table 2), were classified through MLC using the combined PCR and $G_{i}$ clustering results as input.

\section{Methods}

\section{Land-use information entropy model}

Regional landscape heterogeneity is the consequence of interactions between humans and their surrounding natural environment and is determined by structural land use attributes such as connectivity, diversity, and fragmentation (Gaucherel, 2009; Valbuena, Verburg, Bregt, \& Lightenberg, 2010). Landscape heterogeneity often varies between rural and downtown areas (Kane

Table 1

Landsat images used in the study.

\begin{tabular}{lll}
\hline Sensor & WRS-2 path/row & Date acquired \\
\hline Landsat5 TM & $123 / 039$ & $08 / 03 / 1987,08 / 12 / 1994$ \\
& $123 / 038$ & $09 / 10 / 1987,08 / 12 / 1994$ \\
& $122 / 039$ & $09 / 19 / 1987,10 / 24 / 1994$ \\
Landsat7 ETM+ & $123 / 039$ & \\
& $123 / 038$ & $10 / 13 / 2002,09 / 17 / 2010$ \\
& $122 / 039$ & $10 / 13 / 2002,09 / 27 / 2010$ \\
& & $11 / 07 / 2002,10 / 28 / 2010$ \\
\hline
\end{tabular}

et al., 2014; Lopez, Bocco, Mendoza, \& Duhau, 2001; Mohan, Pathan, Narendrareddy, Kandya, \& Pandey, 2011; Schneider \& Woodcock, 2008; Siciliano, 2012; Tian, Qi, \& Zhang, 2012), reflecting differences in land-use diversity including patch size and land-use class types (Haregeweyn et al., 2012; McGarigal \& Marks, 1995; Plexida, Sfougaris, Ispikoudis, \& Papanastasis, 2014). Recently, entropy theory has been shown to be capable for analyzing land-use diversity (Morelli, Pruscini, Santolini, \& Perna, 2013). According to the Shannon entropy index (Shannon, 1949), the land-use information entropy (LUIE) model for characterizing land-use diversity from gridded land-use maps is defined as:

$L U I E=-\sum_{i=1}^{n} P_{i} \log _{\mathrm{e}} P_{i}$

where LUIE refers to the value of land-use information entropy, $\log _{e}$ is the natural logarithm, $P_{i}$ is the area proportion $\left(X_{i} / \sum_{i=1}^{n} X_{i}\right)$ of the $i$-th patch, $X_{i}$ is the area of the $i$-th patch, and $n$ is the total number of patches in the zone. The zones for calculating LUIE are

Table 2

Land-use classes used in the study.

\begin{tabular}{ll}
\hline Land-use classes & Description \\
\hline Impervious areas & $\begin{array}{l}\text { Areas containing artificial surfaces including residential, } \\
\text { commercial, industrial areas, and transportation } \\
\text { infrastructure. }\end{array}$ \\
Water & $\begin{array}{l}\text { Lakes, rivers, ponds, marshlands, and other water bodies. } \\
\text { Cropland, forest, garden plots, and areas covered with } \\
\text { Vegetation }\end{array}$ \\
Others & Bare land and other land covers not mentioned above. \\
\hline
\end{tabular}


predetermined grid squares of a specific size that comprise multiple map pixels. By replacing the $P_{i}$ with $X_{i} / \sum_{i=1}^{n} X_{i}$, the above formula can also be expressed as:

LUIE $=-\sum_{i=1}^{n}\left[\left(X_{i} / \sum_{i=1}^{n} X_{i}\right) \log _{e}\left(X_{i} / \sum_{i=1}^{n} X_{i}\right)\right]$

Through mathematical derivations we obtain:

$L U I E=\log _{e} \sum_{i=1}^{n} X_{i}-\left(\sum_{i=1}^{n} X_{i} \log _{e} X_{i}\right) / \sum_{i=1}^{n} X_{i}$

With a given grid size, the pixel area $\left(\sum_{i=1}^{n} X_{i}\right)$ is constant. By replacing $\sum_{i=1}^{n} X_{i}$ with $S$, Equation (3) can be reduced to:

$L U I E=\log _{e} S-\left(\sum_{i=1}^{n} X_{i} \log _{e} X_{i}\right) / S$

LUIE values range from 0 to $\infty$. A value of 0 indicates the landuse distribution is compact and homogeneous, while high values indicate fragmented landscapes. Land use transformations frequently occur near the UB, and therefore these areas typically exhibit the highest LUIE values (Han et al., 2009). LUIE values will also generally increase with increasing distance from the city center. By identifying the highest LUIE values between the city center and rural fringe, the UB can be mapped. Additionally, landuse diversity often varies at different spatial scales (Aguilera, Valenzuela, \& Botequilha-Leitão, 2011), therefore LUIE values will vary with grid size as well. Large, homogenous areas such as water, impervious surfaces, and vegetation will typically contain a single land-use type in a grid cell and generate LUIE values of 0 . In contrast, LUIE values for areas bordering the urban fringe will vary with changing grid size. The impact of grid size on LUIE computation and UB identification should be examined, and the size of grid cells adopted should be optimized through performance evaluation. This will be discussed in the Results section.

\section{UB extraction framework}

LUIE values reflect the complexity of land-use in each grid cell. Accordingly, LUIE values in the center of urban and rural areas should be lower than those in the intermediate zones. Likewise, homogeneous urban and rural areas will likely be bordered by more complex land use activities. To extract the UBs, instead of using an arbitrary LUIE threshold, profile maps of LUIE are first extracted by searching for cells with the highest LUIE value along radii from the center of the largest built-up patch of each administrative area out to the margins (Fig. 2). The pixel where the LUIE attains its maximum value can be regarded as the UB.

During this procedure, we adopt a search step length coincident with the raster size of the LUIE distribution. Grid points with the highest LUIE value along each radius should be filtered to remove abnormal points that are not initial constituents of the UB before final extraction. These points usually exist in three situations: (a) small urban open spaces such as green parks, hills, or wetlands, (b) areas with compact patches or mixed impervious areas, vegetation, or water away from the UB, and (c) narrow mixed urban belts near the boundary (Fig. 3). The first two situations would not be considered urban boundary. For the third situation, spatial interpolation (e.g., ordinary Kriging) can be used to extract the exact UB by providing a finer-resolution value for the LUIE. If the identified largest impervious patch is a concave polygon, it can be divided into patches for extracting the UB (see Fig. 2).

\section{Kriging interpolation}

Kriging is a geostatistical interpolation technique that uses a weighted average of neighboring values to estimate unknown values at a given location (Krige, 1951; Mantheron, 1963). Kriging follows the equation:

$Z\left(x_{0}\right)=\sum_{i=1}^{m} w_{i} Z\left(x_{i}\right)$

where $Z\left(x_{0}\right)$ is the value to be estimated at the location of $x_{0}, Z\left(x_{i}\right)$ is the known value at the site of the $i$-th sample $x_{i}, w_{i}$ is a weight, and $m$ is the number of sites, which is defined by the user as the size of the moving search window.

Using Kriging, a comparative analysis is carried out to test the impacts of scale on the location of the UB. First, LUIE is calculated for grids with cell sizes of $100 \mathrm{~m}, 200 \mathrm{~m}, 400 \mathrm{~m}, 600 \mathrm{~m}, 800 \mathrm{~m}$, $1000 \mathrm{~m}$ and $1200 \mathrm{~m}$. Second, ordinary Kriging is performed using the LUIE points to generate a continuous LUIE surface with a final raster resolution of $30 \mathrm{~m}$. Finally, the UB is extracted from the original LUIE distribution (non-kriged) and kriged surface, respectively. Accuracy of the extracted UB is assessed for each grid cell size in order to ultimately optimize the process.

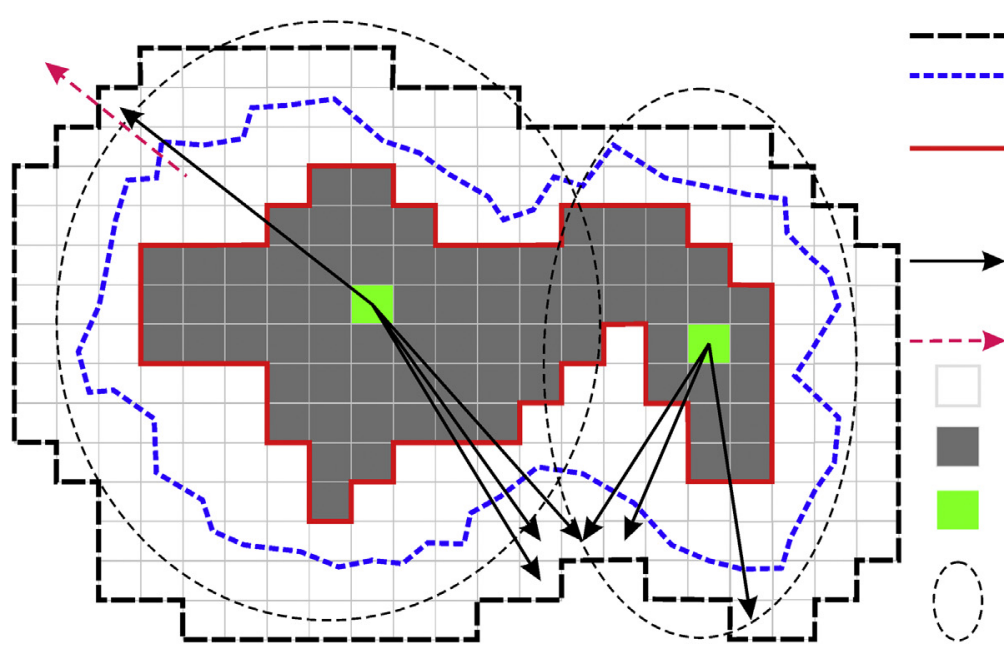

Administrative boundary

Urban Boundary(UB)

The boundary of the largest

impervious patch in the administrative district Radius from the center of the largest impervious patch in the administrative district Searching directions LUIE distribution pixels Pixels with lower values of LUIE

Centers of urban areas

Parts of UBs that should be extracted respectively

Fig. 2. Method for UB extraction and the schematic diagram. 


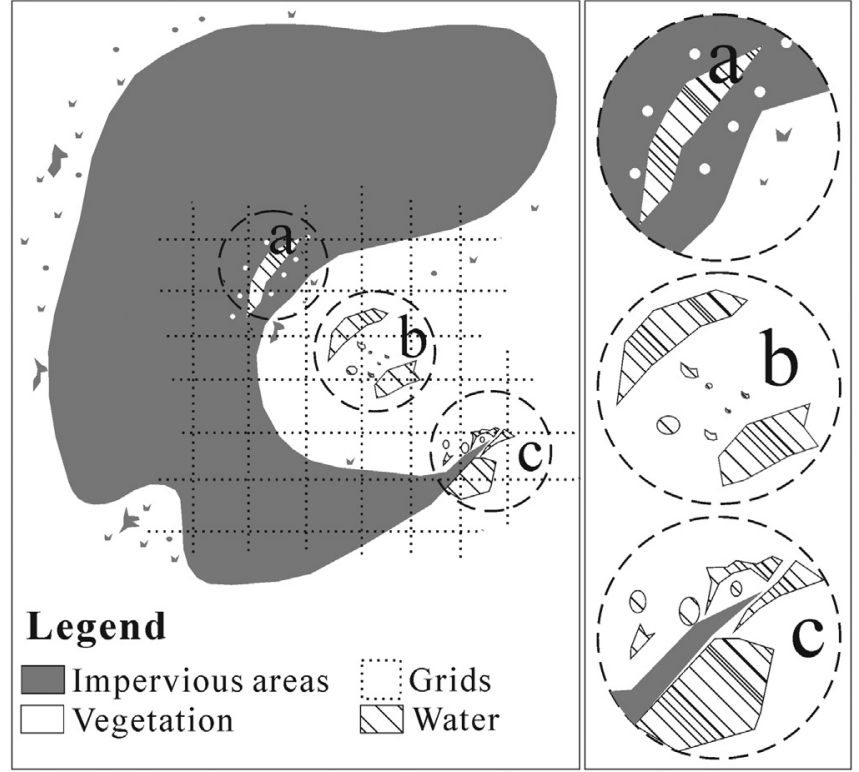

Fig. 3. Atypical situations that should be noted when extracting UBs. Several areas of heterogeneity can be encountered including (a) open spaces within urban areas, (b) cells grouped with open spaces away from the urban fringe, and (c) mixed narrow urban belts.

\section{Urban growth analyses}

\section{Annual growth rate}

Using the method described above, UBs are extracted for each administrative region in Wuhan from Landsat images $(1987,1994$, 2002, 2010). Annual Growth Rate (AGR) is calculated following (Taubenböck et al., 2014):

$A G R=\left(\sqrt[i]{A_{t+i} / A_{t}}-1\right) \times 100 \%$

where $A G R$ is the annual urban growth rate for the period from $t$ to $t+i$. $A_{t}$ and $A_{t+i}$ are the area of urban land in time $t$ and $t+i$, respectively, and $i$ is the time interval.

\section{Box-counting dimension}

Fractals are objects with the geometric property of selfsimilarity, meaning that each portion can be considered as a reduced-scale image of the whole (Mandelbrot, 1967). Accordingly, most natural and social features resemble fractals (Hu et al., 2013; Tannier et al., 2011). The degree of complexity (i.e., fractal dimension) can be used to measure the complexity of features. The higher the fractal dimension, the more complex the geometry. Fractal geometry allows for analyzing complex process by overcoming the rigidity of Euclidean geometry, therefore it provides a useful means for describing urban form and characterizing expansion (Jafari \& Babadagli, 2013; Tannier \& Thomas, 2013). The box-counting method operates by breaking a dataset into smaller box-shaped pieces to investigate patterns:

$D=\lim _{\varepsilon \rightarrow \infty}\left[\log _{e} N(\varepsilon) / \log _{e}(1 / \varepsilon)\right]$

where $D$ is the box-counting dimension and $N(\varepsilon)$ is the measured magnitude of the boxes of size length $\varepsilon$ covering the measured object. The value of $D$ reflects the irregularity of an object whereby a high value of $D$ indicates the object is highly irregular. In this study, the box-counting dimension $(D)$ is adopted as a measure of the irregularity of the UB.

\section{Landscape metrics}

Dramatic land-use changes also affect urban form through altering the patterns of the landscape. Landscape metrics such as patch density (PD), largest patch index (LPI), landscape shape index (LSI), mean fractal dimension index (FRAC_MN), Shannon's diversity index (SHDI), and the interspersion juxtaposition index (IJI), are significant indicators for evaluating landscape attributes such as diversity, connectivity, and fragmentation (Gaucherel, 2009; McGarigal \& Marks, 1995). Integrated PD and LPI metrics are useful for analyzing urban sprawl patterns (Taubenböck et al., 2014). High PD and low LPI values usually reveal dispersed expansion patterns. Similarly, LSI, FRAC_MN, IJI and SHDI are widely used for landscape connectivity and diversity research (Patino \& Duque, 2013). Increasing LSI, FRAC_MN and IJI are indicators of interspersed landscapes. The six landscape-level metrics mentioned are adopted here to measure the impacts of urban sprawl at different spatial scales including local administrative districts as well as the entire regional Wuhan extent.

\section{Results}

\section{Assessment of the UB extraction method}

The performance of the UB extraction at different scales is compared. To recap, first the regional LUIE distributions of Wuhan in 2010 were computed for grids with a pixel size of $100 \mathrm{~m}, 200 \mathrm{~m}$, $400 \mathrm{~m}, 600 \mathrm{~m}, 800 \mathrm{~m}, 1000 \mathrm{~m}$ and $1200 \mathrm{~m}$, respectively. Then, fineresolution $(30 \mathrm{~m})$ LUIE maps were generated through ordinary Kriging interpolation. Results indicate large differences between LUIE distributions when computed for the different resolutions (Fig. 4). The proportion of pixels possessing high LUIE values increases with grid size, which is particularly pronounced in the areas surrounding the downtown. Low LUIE values are generally obtained in the central downtown, the mountainous areas of northwestern and northeastern Wuhan, and the districts mainly covered by water and vegetation in southwestern Caidian, Hannan, and southeastern Jiangxia. Despite the varied ranges of local LUIE, regional land-use diversity generally increases with increasing grid size from $100 \mathrm{~m}$ to $1000 \mathrm{~m}$ (Fig. 5). Narrow LUIE ranges and low mean LUIE values are observed for the $1200 \mathrm{~m}$-resolution LUIE as well as the interpolated surfaces in all study regions. Standard deviation (StdDev) curves, an indicator measuring the discreteness of the dataset, show that increasing heterogeneity of LUIE distributions occurs in almost all regions with as pixel size increases from $100 \mathrm{~m}$ to $1000 \mathrm{~m}$. Furthermore, the ranges of the kriged LUIE values are relatively more confined than those of the non-kriged LUIE values. The kriged LUIE output from the 600 m-resolution LUIE shows the widest range in LUIE values.

LUIE curves of Hankou in 2010 along three directions indicate that the regional LUIE distributions are anisotropic (Fig. 6). The curves plotted for the $800 \mathrm{~m}$ LUIE and the associated kriged outcome show different shapes. The curves along the northeastern and northwestern radii have a single peak, while several peaks are observed in the LUIE curve along the southwestern radius. Comparatively, curves plotted from the original LUIE map are relatively smoother than those delineated from the kriged map. Furthermore, the varying LUIE curves and corresponding local land-use diversity are closely related. Areas inside the urban extent of Hankou contain fragmented open spaces, such as Xibei Lake, Zhongshan Park, Houxianghe Park, and Changqing Park, which possess high local land-use diversity and create the abnormal heights of the LUIE curves (Fig. 6-a). These peaks generate the trough in the LUIE curves where the urban areas are located (Fig. 6b). Complex land-uses in the more remote Hankou are shaped by the intense land transformations and insular units grouped with 

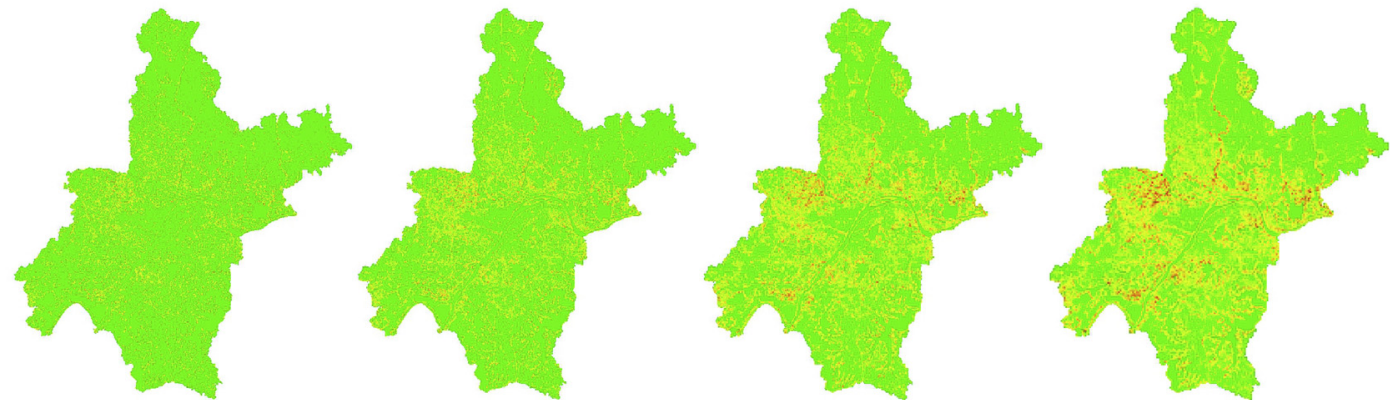

$100 \mathrm{~m}$ (no Kriging)

200m(no Kriging)

400m (no Kriging)

$600 \mathrm{~m}$ (no Kriging)
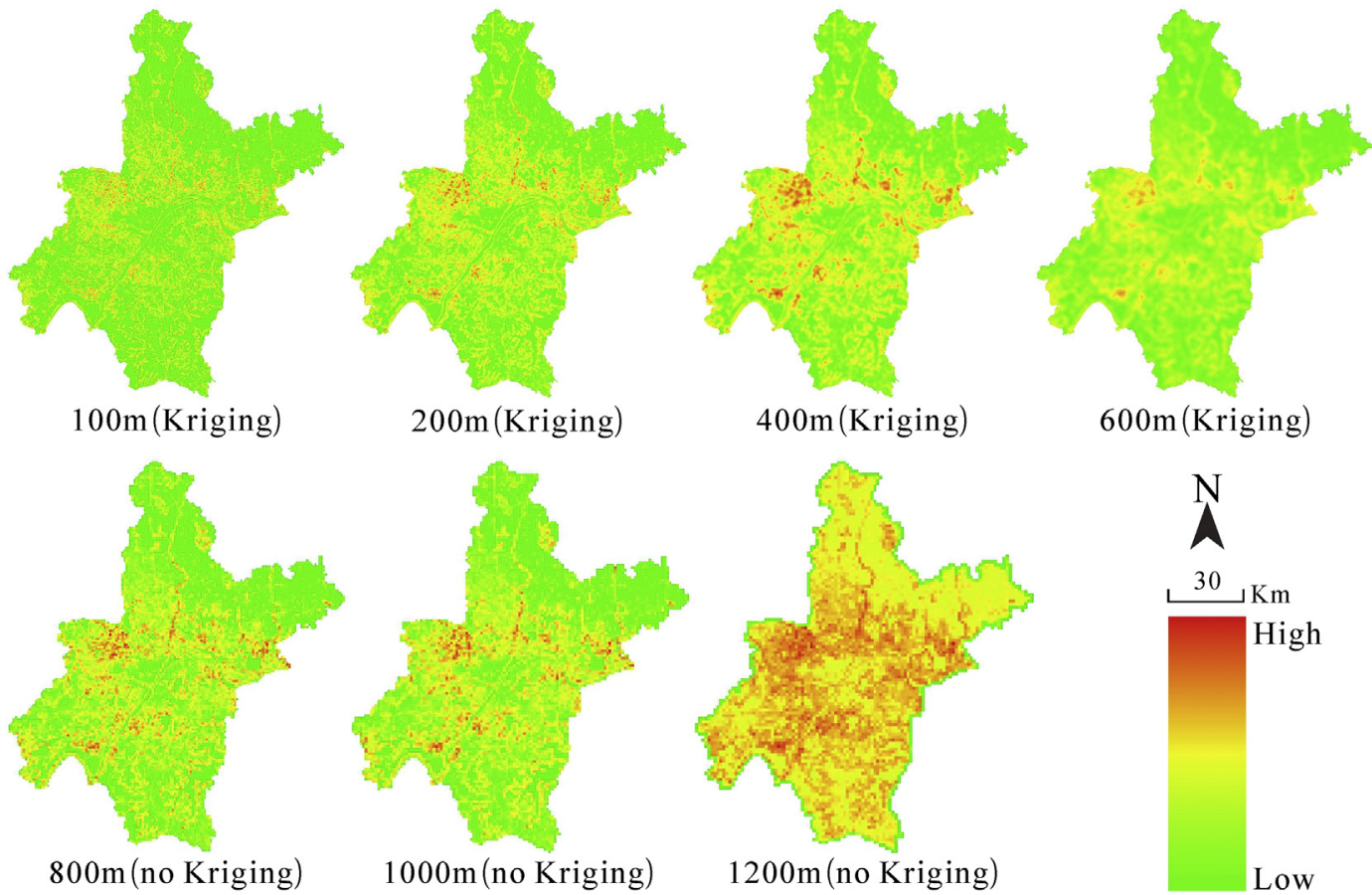

$400 \mathrm{~m}$ (Kriging)

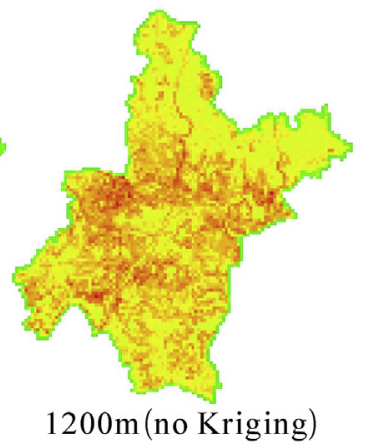

$600 \mathrm{~m}$ (Kriging)

$800 \mathrm{~m}$ (no Kriging)
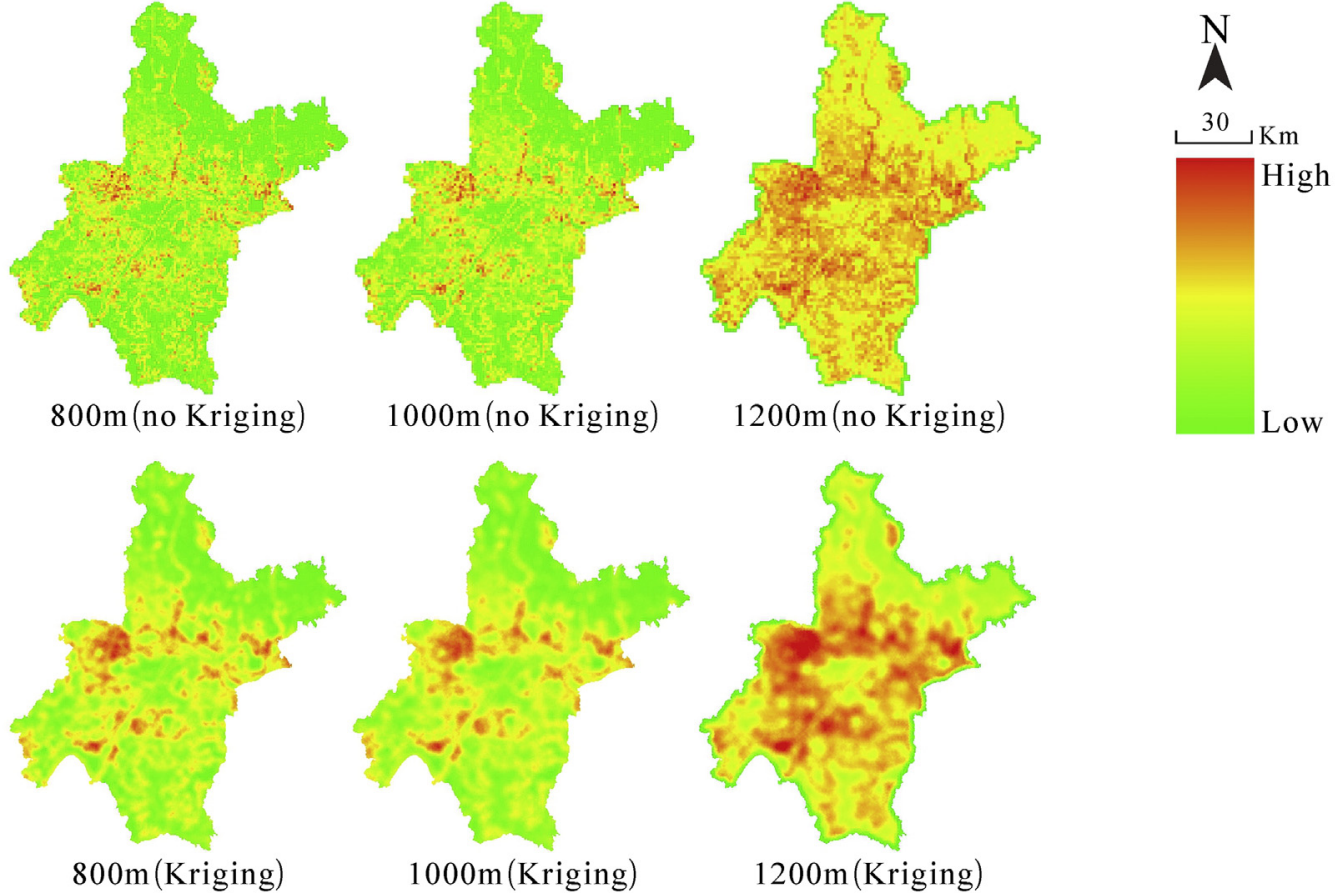

Fig. 4. LUIE distributions for Wuhan, China in 2010.

cropland, ponds and rural settlements, which also leads to peaks in the LUIE curves (Fig. 6-d). The above-mentioned situations do not accurately indicate urban areas and should be rejected when identifying UBs. Locations with the highest local LUIE values are in fact suitable indicators for the UB (Fig. 6-c). The optimal LUIE values adopted for indicating the UB located are varied. Along the three radii in Hankou (northeastern, northwestern, and southwestern), the LUIE values of the UB at the $800 \mathrm{~m}$ resolution are $1.21,1.17$, and 1.03 , respectively. Optimal values for the kriged LUIE are 1.20, 0.92, and 0.70 , respectively. These results indicate that using absolute LUIE thresholds to identify the UB would be erroneous.
The actual UBs of Hankou, Dongxihu, Hannan, and Huangpi were obtained from a land use map created in 2010 by the DLRH. Actual and identified UBs of Hankou, Dongxihu, Hannan, and Huangpi in 2010 are shown in Fig. 7. The urban areas of Hankou and Dongxihu were agglomerated in 2010 (Fig. 7a, d), and the respective boundary cannot be distinguished from the LUIE distribution. Hence, the extracted UB contains the entire urban areas of Hankou and Dongxihu (Hankou-Dongxihu region).

The results shown in Fig. 7 support the concept that urban areas are formed not only by impervious surfaces but also by natural spaces including green spaces and lakes (Hollis, 2013). Results also 

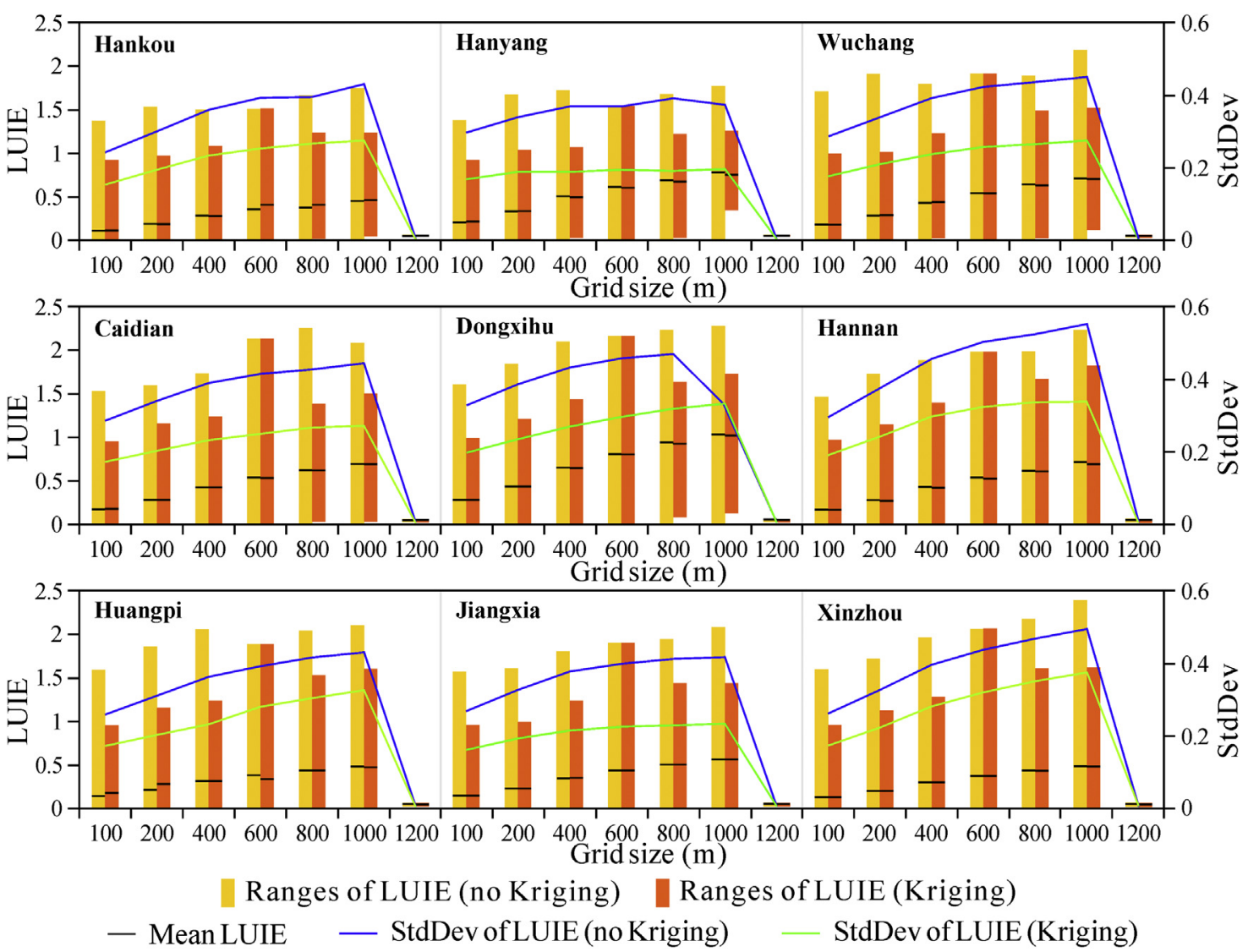

Fig. 5. Statistics for the LUIE distributions in Wuhan, China in 2010.

show the varying performance of the UBs extracted from different resolution LUIE maps ( $800 \mathrm{~m}$ vs. $1000 \mathrm{~m}$ ). These results support the optimization of grid size according to local land-use diversity when computing the LUIE as it can improve the effectiveness of UB extraction. Generally, differences between the extracted and actual UBs were observed in areas possessing higher land-use diversity.

Based on the actual and extracted UBs, thematic maps of true and classified urban areas within a minimum circle extent that could synchronously contain both the true and extracted UBs were composed. Then, we developed a confusion matrix for assessing the performance of the UB. Results show mixed accuracies for overall accuracy (OA) and the kappa coefficient (KC) (Fig. 8). For Hankou and Dongxihu, accuracy varies from $100 \mathrm{~m}$ to $800 \mathrm{~m}(\mathrm{OA} / \mathrm{KC}$, $97.03 \% / 0.9261)$ using the kriged and non-kriged LUIE. A continuous decrease in accuracy is then observed for both sets of results at the coarsest resolutions. The non-kriged LUIE outperformed the kriged surfaces for UB extraction in Hannan at $100 \mathrm{~m}, 200 \mathrm{~m}, 400 \mathrm{~m}$, $600 \mathrm{~m}, 1000 \mathrm{~m}$ and $1200 \mathrm{~m}$. However, significant accuracy improvement is seen for the $800 \mathrm{~m}$ results, which had an OA of 92.71\% and a KC of 0.925. In contrast, the differences between the multi-scale LUIE-based UB extraction in Huangpi were relatively inconspicuous. The original $600 \mathrm{~m}, 800 \mathrm{~m}$ and $1000 \mathrm{~m}$-resolution
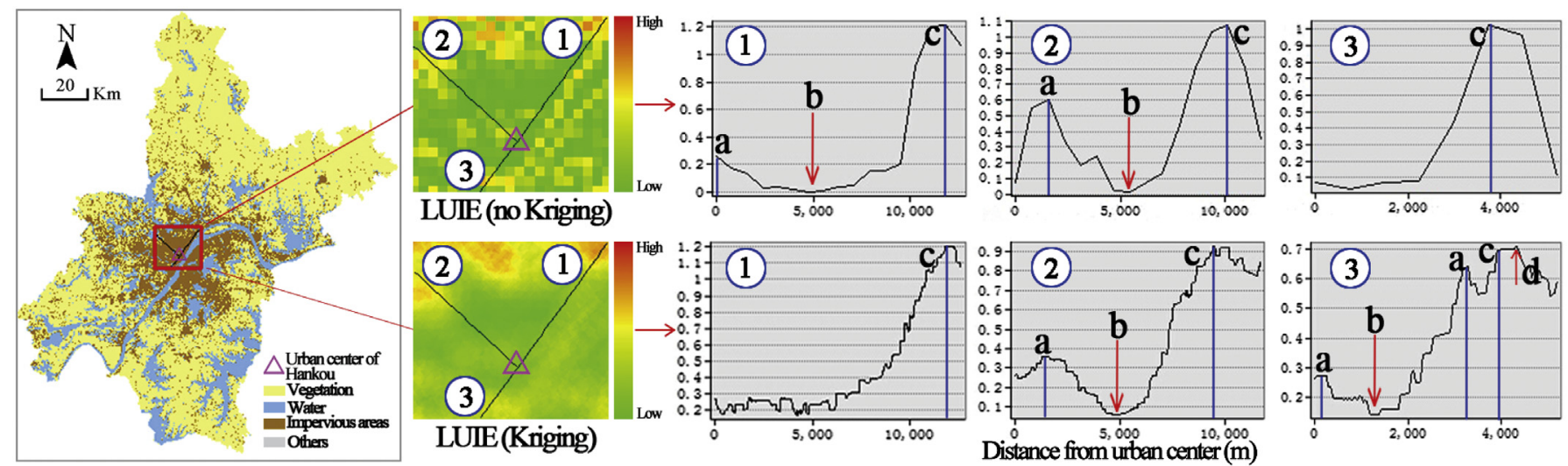

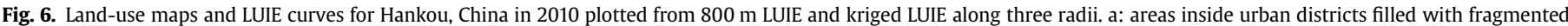

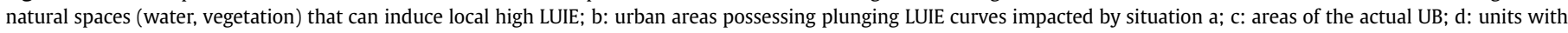
water, vegetation, and impervious surfaces remote from the urban fringe but generating high LUIE values. 


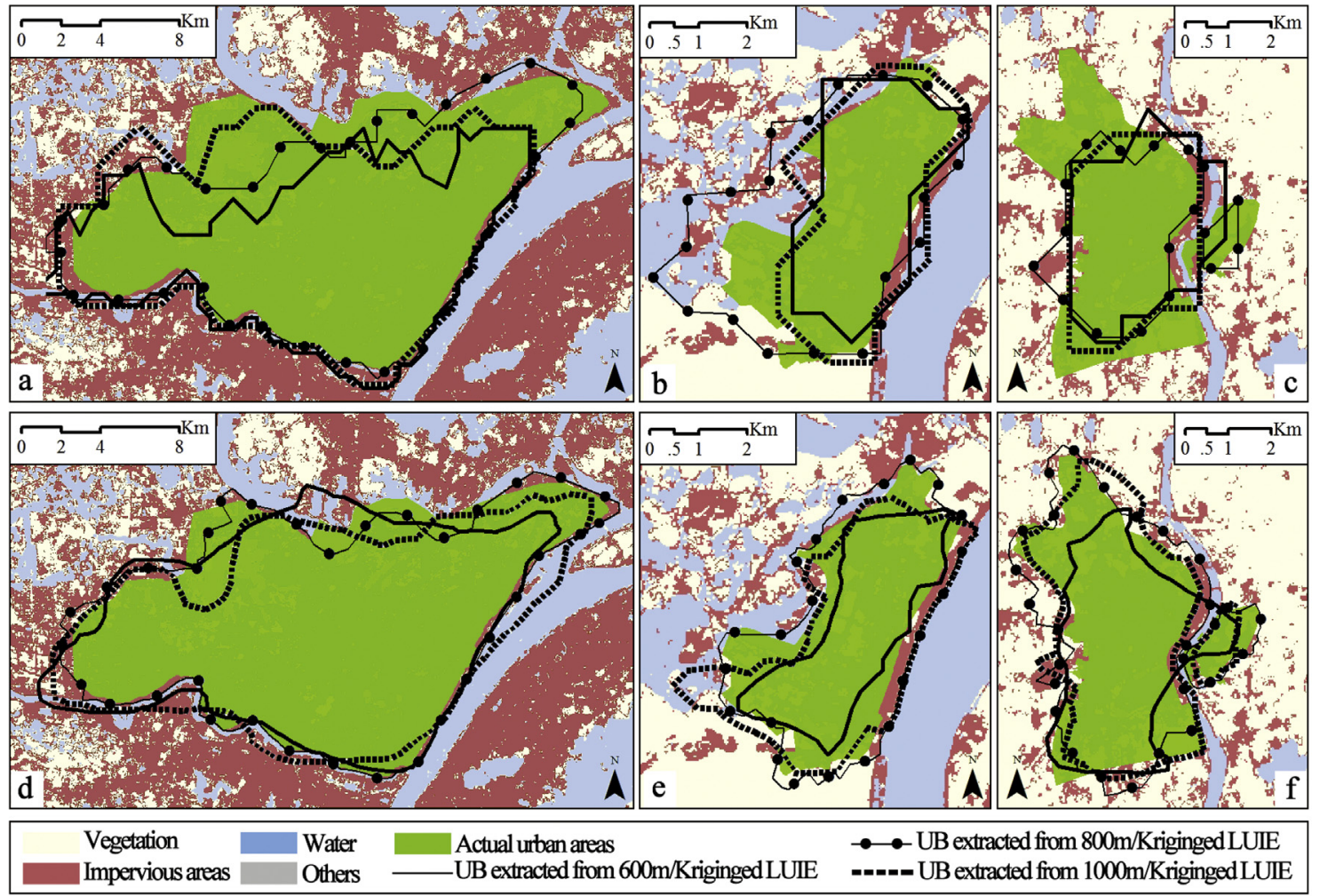

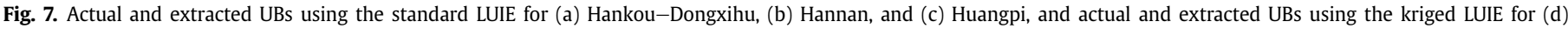
Hankou-Dongxihu, (e) Hannan, and (f) Huangpi.

LUIE more accurately identified the UB. Although the highest accuracy for Huangpi was generated using the kriged $1000 \mathrm{~m}$ LUIE, it is worth noting that the OA from the kriged $800 \mathrm{~m}$ LUIE was also quite high $(\mathrm{OA}=90.55 \%)$. Accordingly, the $800 \mathrm{~m}$ grid size integrated with Kriging was continually the most reliable for extracting UBs and was therefore adopted for UB identification in the remainder of the study (Fig. 9).

\section{Urban growth for period 1987-2010}

Table 3 shows rapid urban sprawl with an AGR of $8.57 \%$ in Wuhan. Urban areas increased from $11,407.84$ ha to $75,602.28$ ha during the period 1987-2010 (Table 4). The downtown, which was the major site where expansion occurred, comprised $89.08 \%$
(6481.3 ha) and $89.54 \%$ (9982.65 ha) of the total growth during the first two periods 1987-1994 and 1994-2002, respectively. However, urban sprawl slowed after that as it was impacted by declining space for development, increasing ecological protection policies, industrial restructuring, land-use transformations, and urban-rural development. Instead, growth increased in the suburbs, especially Caidian, Dongxihu, Huangpi, and Jiangxia. From 2002 to 2010, the most intense expansion occurred in these areas, and they account for almost $85 \%$ of the total increase of urban land $(64,194.43 \mathrm{ha})$ since 1987 and are accompanied by an AGR of 12.33\%. Furthermore, 17.6\% ( $8063.24 \mathrm{ha}$ ), 15.5\% (7082.71 ha), and $10.5 \%$ (4812.27 ha) of the total increase in growth was observed in Dongxihu, Jiangxia, and Caidian, respectively. Clearly, growth rates vary throughout the local districts of Wuhan. Generally, the
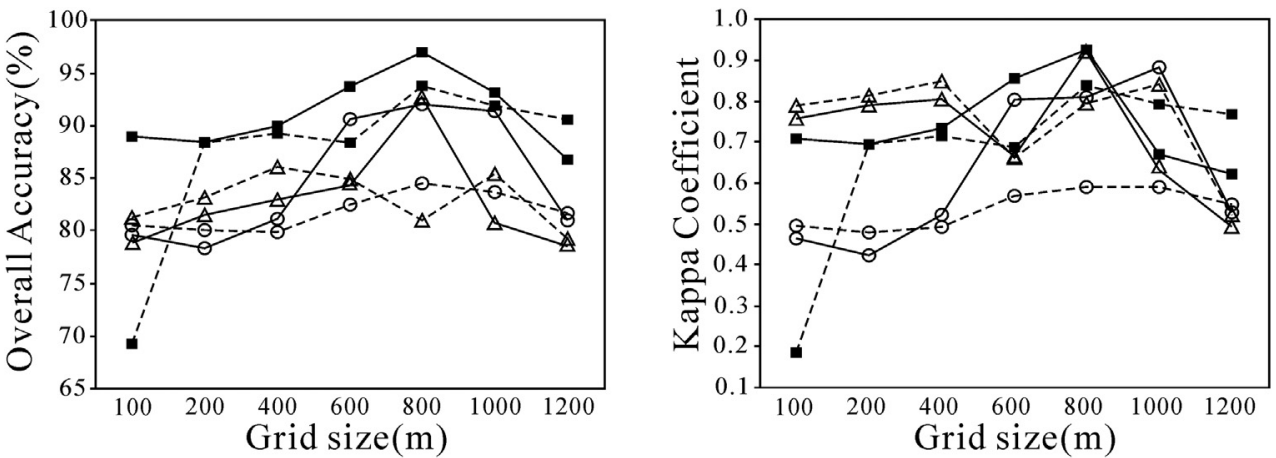

-Hankou and Dongxihu(Kriging) $\triangle$ Hannan(Kriging) $\quad-$-Huangpi(Kriging)

--Hankou and Dongxihu(no Kriging) - - - -Hannan(no Kriging) - - -- -Huangpi(no Kriging)

Fig. 8. Accuracy of UB extraction at various resolutions. 

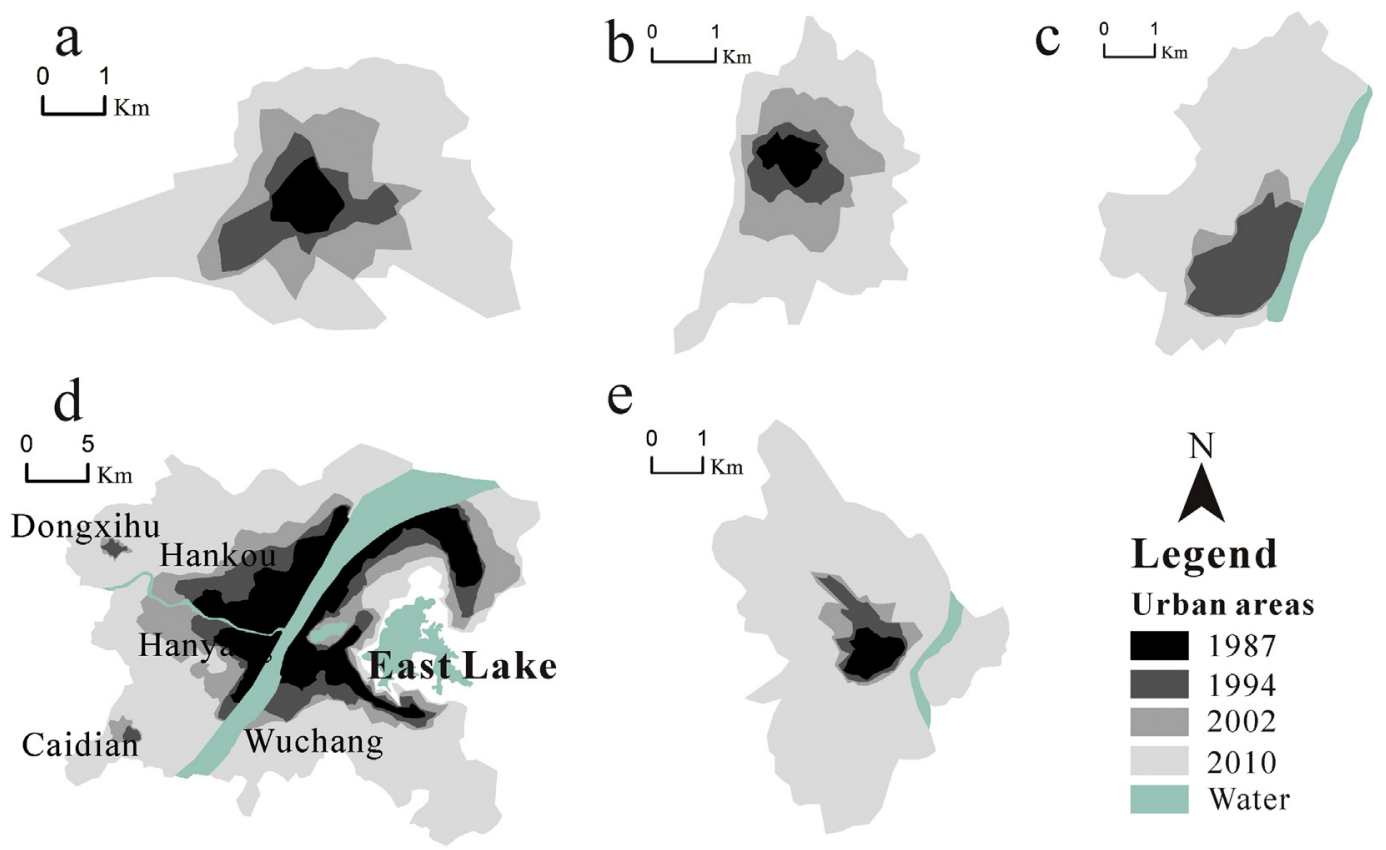

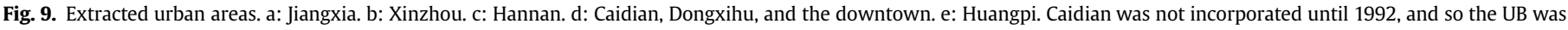
not extracted in 1987. The urban areas of Hankou and Dongxihu (Hanyang and Caidian) were agglomerated in 2010.

suburbs experience small spatial increases in urban areas with higher AGRs, while the downtown experiences large-scale increases in urban areas with relatively stable and low AGR. The AGRs of the downtown during the study periods are all below $11 \%$, while the suburbs exceed that of the downtown and overall Wuhan. Particularly, for the third period 2002-2010, intense development of industrial and residential land contributes to a high local AGR in Dongxihu (54.3\%) and Caidian (38\%). The reconstruction of the host town, expansion of universities, and unchecked development of commercial and recreational lands are the causative forces driving the high pace of urban sprawl occurring in Huangpi and Jiangxia. Xinzhou is the only district that has witnessed decreasing AGRs since 1987.

Multi-scale landscape dynamics occurred in Wuhan during 1987-2010

The box-counting dimensions show relatively weak dynamics for the UBs during 1987-2010 in both the suburbs and downtown (Table 5). In general, the dimensions contract for all urban areas of Wuhan after 1987. During the period 1987-1994, slightly decreased dimensions are observed for the downtown and Xinzhou

Table 3

Annual Growth Rate (AGR) (\%) of urban areas for the period 1987-2010.

\begin{tabular}{lcccc}
\hline District & $1987-1994$ & $1994-2002$ & $2002-2010$ & $1987-2010$ \\
\hline Hankou & 6.83 & 5.8 & 7.39 & 6.66 \\
Hanyang & 6.79 & 10.34 & 9.43 & 8.93 \\
Wuchang & 7.19 & 5.75 & 7.38 & 6.75 \\
Dongxihu & 17.06 & 6.66 & 54.33 & 24.77 \\
Caidian & - & 15.27 & 38.00 & 26.12 \\
Hannan & 16.7 & 2.97 & 19.99 & 12.81 \\
Huangpi & 11.54 & 5.68 & 36.07 & 17.3 \\
Jiangxia & 16.8 & 11.07 & 36.35 & 21.12 \\
Xinzhou & 14.55 & 13.97 & 13.05 & 13.82 \\
Overall & 7.30 & 6.02 & 12.33 & 8.57
\end{tabular}

Note: The UB for Caidian in 1987 was not extracted because it was not a recognized district until 1992. indicating homogeneous urban growth. Suburbs with relatively large-scale sprawl and low AGRs, notably Dgongxihu and Jiangxia, saw increasing dimensions. During the second period from 1994 to 2002, the dimension increased in Hankou, Hanyang, Caidian, Dongxihu, and Huangpi, while it decreased in Wuchang, Hannan, Jiangxia, and Xinzhou. Further analysis shows that suburbs that possess high AGRs and accelerated expansion rates usually generate decreasing box-counting dimensions. During the final stage from 2002 to 2010, dimensions decreased for all regions except Caidian, Dongxihu, Huangpi, and Jiangxia. The factors shaping urban morphology are mixed (Elmqvist et al., 2013; Tannier \& Thomas, 2013). Impacted by the local topography and land-use distribution including water bodies and forests, high dimensions were still obtained during the rapid urban growth in Hanyang, Wuchang, Hannan and Xinzhou. Meanwhile, due to the compact industrial and residential land use and improvement of public facilities, Hanyang generated a less complex UB after 2002.

In the districts profoundly influenced by human activities, specifically urban construction, landscape metrics show similar dynamics over time. In general, the downtown exhibited increasing LPI and falling PD in both the local regions and urban extents (Fig. 10a-c). Consequently, decreasing LSI and SHDI were observed

Table 4

Area (ha) of urban areas in 1987 and urban growth over the period 1987-2010.

\begin{tabular}{lrrrr}
\hline District & Urban areas in 1987 & \multicolumn{3}{c}{ Newly increased urban areas } \\
\cline { 3 - 5 } & & $1987-1994$ & $1994-2002$ & $2002-2010$ \\
\hline Hankou & 3946.19 & 2106.31 & 2169.52 & 4984.68 \\
Hanyang & 1349.55 & 787.90 & 2557.57 & 4960.34 \\
Wuchang & 5731.03 & 3587.09 & 5255.56 & $11,185.12$ \\
Dongxihu & 51.25 & 103.15 & 104.16 & 8063.24 \\
Caidian & - & 127.08 & 268.97 & 4812.27 \\
Hannan & 107.29 & 208.91 & 83.51 & 1317.64 \\
Huangpi & 75.51 & 86.67 & 90.21 & 2714.29 \\
Jiangxia & 94.22 & 185.15 & 367.53 & 7082.71 \\
Xinzhou & 52.79 & 83.87 & 252.41 & 648.59 \\
Overall & $11,407.84$ & 7276.13 & $11,149.43$ & $45,768.87$ \\
\hline
\end{tabular}


Table 5

UB box-counting dimensions.

\begin{tabular}{lllll}
\hline District & 1987 & 1994 & 2002 & 2010 \\
\hline Hankou & 1.0061 & 0.9981 & 1.0018 & 1.0039 \\
Hanyang & 1.0261 & 1.0231 & 1.0427 & 1.0067 \\
Wuchang & 1.0403 & 1.0137 & 1.0094 & 1.0116 \\
Caidian & - & 1.0545 & 1.0755 & 1.0039 \\
Dongxihu & 1.0149 & 1.0751 & 1.0896 & 1.0067 \\
Hannan & 1.0051 & 1.0278 & 1.0214 & 1.0291 \\
Huangpi & 1.0925 & 1.1098 & 1.1176 & 1.0896 \\
Jiangxia & 1.0243 & 1.1152 & 1.0714 & 1.0454 \\
Xinzhou & 1.1141 & 1.0429 & 1.0259 & 1.0779 \\
Overall & 1.0879 & 1.0701 & 1.0664 & 1.0539 \\
\hline
\end{tabular}

in Hankou, Hanyang, and Wuchang, which are experiencing rapid urbanization. However, in the suburbs where small towns area located, landscape pattern dynamics are mixed. Decreasing LPI in all of the suburban regions reveals the loss of dominance of vegetation/water during 1987-1994 due to urban sprawl (Fig. 10d-i). However, in the urban areas of Huangpi, Jiangxia, and Xinzhou impervious surface dominates the local landscape, and LPI increases in line with sprawl (Fig. 10f, g, i). As a result, the loss of SHDI occurs. For the suburbs Caidian, Dongxihu, and Hannan, LPI and SHDI are variable suggesting intensive land-use transformations during urban expansion (Fig. 10d, e, h). Variations such as these typically result from complex human activities and policies including environmental protection policies, industrial reconstructing, and agricultural conservation strategies. It is worth noting that the disparate dynamics of LPI, IJI, and SHDI at local scales occur during expansion. Furthermore, significantly different dynamics for IJI in Huangpi and IJI and SHDI in Xinzhou occur during 1987-2002 (Fig. 10f, i). Large differences of LSI at different scales are observed for Caidian, Dongxihu, Huangpi, Jiangxia, and Xinzhou (Fig. 10d-g, i). The shape of the largest patch (usually artificially developed surface) in the urban areas is much more complex than that of the entire region. IJI is sensitive during expansion represented by the variable plot over time, while FRAC_MN is relatively constant across time. As such, IJI appears to be a reliable indicator for multi-scale landscape dynamics.

Lastly, we analyzed the landscape metrics in the regional urban areas and across Wuhan (Fig. 11). The results demonstrate increasing PD and LPI and decreasing LSI and SHDI in regional urban areas of Wuhan. These values suggest constant and compact growth within the Wuhan UB in 2010. However, variable IJI and FRAC_MN values are seen for 1987-2010. It is likely that the natural spaces such as large water bodies, mountain areas, and cropland have great impacts on the regional landscape at this scale. In comparison, LPI, IJI, and SHDI have larger ranges at urban scales, whereas they only change slightly across all of Wuhan.

\section{Discussion}

Automated UB identification using remote sensing is essential for multi-scale sprawl measurements and landscape analyses under rapid urbanization (Chen et al., 2013; Taubenböck et al., 2014). In this study, we proposed a concise framework for UB extraction from Landsat images based on the LUIE model and analyzed the rate of sprawl and associated landscape dynamics for different scales including local and regional administrative districts as well as the entire city of Wuhan.

The method introduced in the study is based on the hypothesis that areas near the urban fringe will generate the highest land-use diversity; thereby allowing the UB to be extracted where the
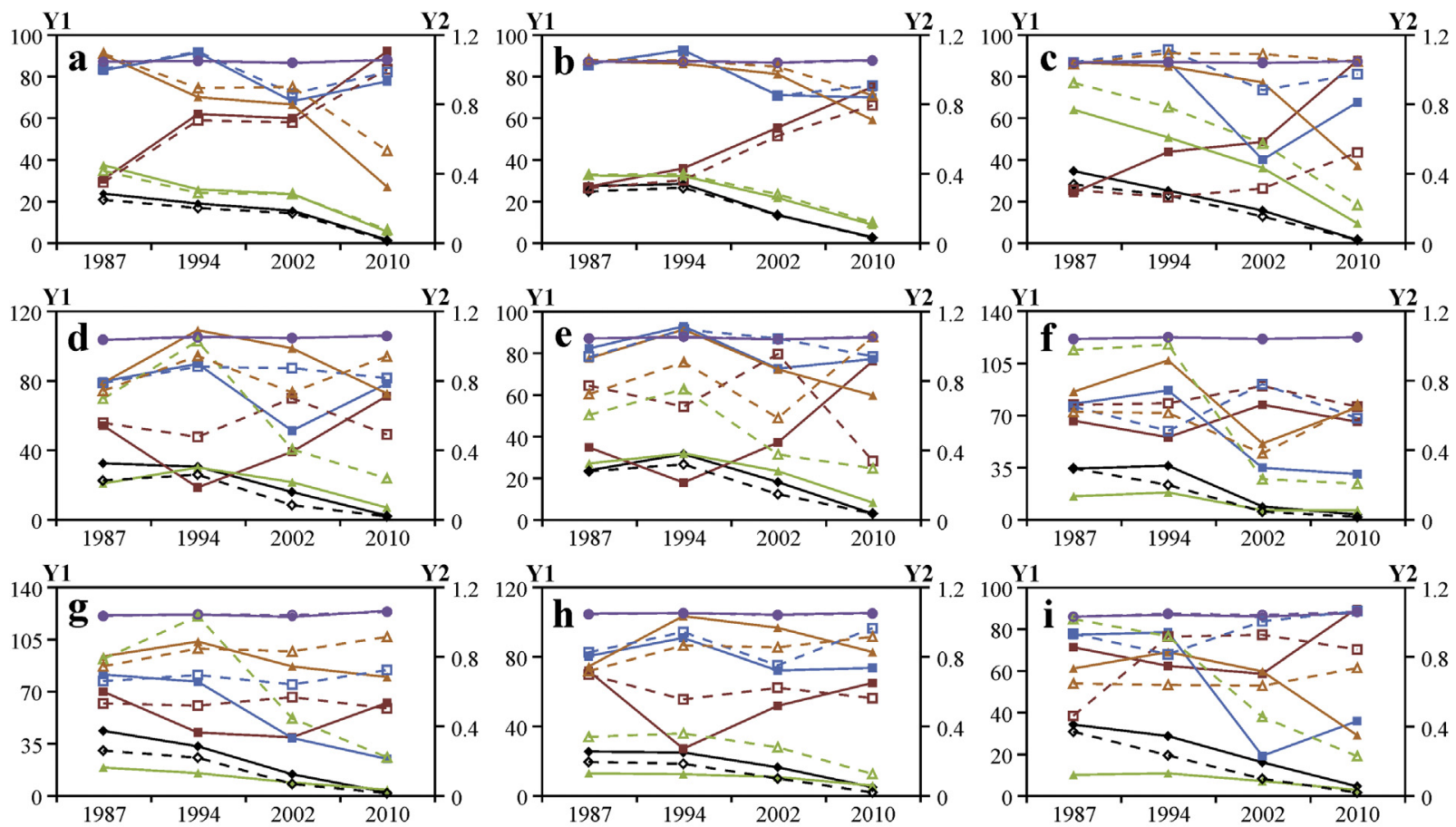

Landscape dynamics in local urban areas

Landscape dynamics in local districts

$$
\begin{aligned}
& \longrightarrow \text { PD } \longrightarrow \text { LPI } \longrightarrow \text { LSI } \\
& \longrightarrow \text { IJI } \longrightarrow \text { SHDI } \longrightarrow \text { FRAC_MN }
\end{aligned}
$$$$
--\diamond-\text { PD }--\square-\text { LPI }--\Delta-\text { LSI }
$$$$
--\square-\text { IJI - - - SHDI - - - FRAC MN }
$$

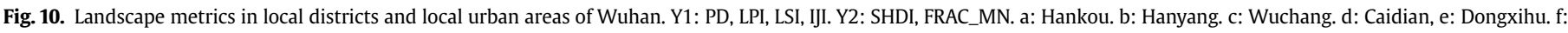
Huangpi. g: Jiangxia. h: Hannan. i: Xinzhou. Note: Local districts refer to downtown and suburbs of Wuhan. Local urban areas are areas within UB (2010) of each local region. 

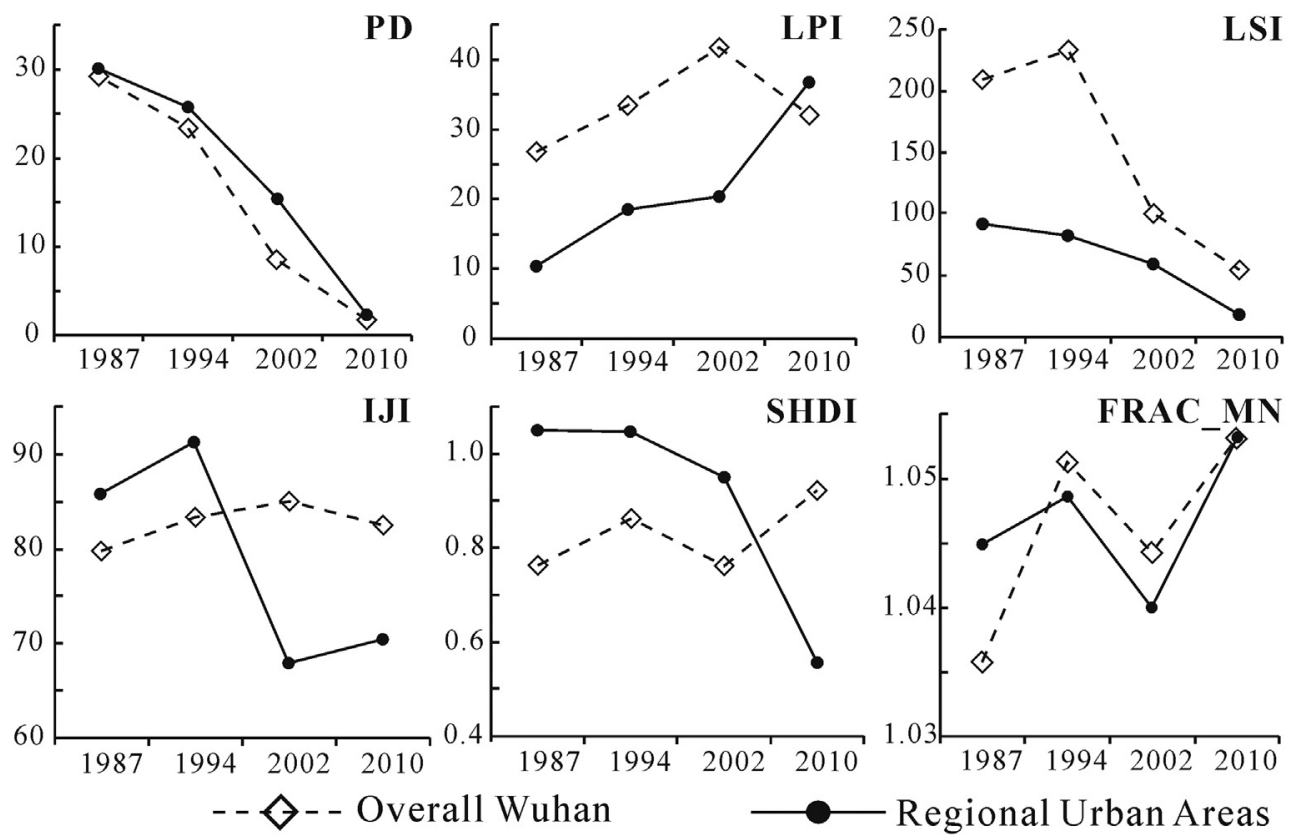

Fig. 11. Landscape metrics of regional urban areas and overall Wuhan, China.

highest land-use diversity occurs. Accordingly, effective UB extraction requires (1) accurate local land-use diversity characterization, (2) land-use diversity hypothesis testing, and (3) recognition of the extents with the highest land-use diversity. Consequently, a LUIE model for computing land-use diversity from gridded land-use maps and a compact framework for searching for high LUIE values along the radii of cities was developed. However, land-use diversity is influenced by land-use patterns, which usually change with study scale (Bhatta et al., 2010; Morelli et al., 2013; Schneider \& Woodcock, 2008). Local land-use diversity will vary with different grid sizes when computing LUIE. Furthermore, grid size is also a causative factor for LUIE resolution that impacts UB extraction. Hence, comparative analyses of LUIE distributions using methods that rely on spatial interpolation to provide fineresolution LUIE surfaces are indeed essential for efficient UB identification.

It is noteworthy that we identified UBs along previously selected directions rather than in abruptly changing areas. Although complex open spaces inside cities and the surrounding fragmented landscapes could confound extraction, they did not seriously hinder the method. This is likely because in most districts, especially in developing countries such as China, the villages and towns in rural districts and their urban open spaces are usually small in size and spatially disperse (Lopez et al., 2001; Siciliano, 2012; Tian et al., 2012). Additionally, these small areas can be profoundly concealed by coarse resolution images (Lausch \& Herzog, 2002; Mairota et al., 2015). The small parks, wetlands, and villages could not theoretically generate abnormally high LUIE values using the optimal grid size of $800 \mathrm{~m}$, for example. Furthermore, individual abnormal values are not likely to subvert the regional LUIE distribution. Certainly, we do not suggest that the situations resulting in abnormally high LUIE inside cities and consequently low LUIE values near the urban fringe be excluded. Rather, the areas generating abnormally highest LUIE values that are a result of local land use anomalies should be identified, assessed, and masked if necessary prior to UB extraction. Large features adjacent to the urban core, such as the East Lake in Wuchang, can result in a low LUIE. In these cases, a priori knowledge of the study area may useful for insuring the performance of UB extraction. Moreover, the results also show that finer-resolution LUIE can improve UB extraction. Ordinary Kriging simulates variation properties based on spatial autocorrelation and thus provides high-resolution distributions of spatial variation (José-Ma \& Beatriz, 2006). Additionally, the method is suitable for analyzing massive spatial datasets (Abedini, Nasseri, \& Ansari, 2008) such as those for complex landscapes showing spatial self-similarity (Gaucherel, 2009). Although the moving weighted average method can inevitably smooth the data and potentially eliminate useful local information (Valeriano et al., 2006), it has been tested to be reliable and efficient in UB identification based on highest LUIE values rather than abrupt changes. The final OAs exceeded $90 \%$ in multi-scale districts, Hankou-Dongxihu, Huangpi and Hannan, which exhibit different local topography. Certainly, there are many methods could be used for interpolating, such as co-Kriging, multifractal inverse distance weighting (IDW) and many others (Hu et al., 2013), and these can be incorporated into future studies.

Under rapid urbanization, landscapes are shaped by social, economic and ecological development modes (Kane et al., 2014). Accordingly, four sprawl patterns showing varied multi-scale landscape dynamics were recognized in the study (Table 6). Stable growth areas (i.e., Hankou, Hanyang and Wuchang) expanded with an increase of new urbanized areas and slightly varying AGRs over time. The compact inner fabric of this urbanization mode led to decreasing PD, LSI, and SHDI and increasing LPI over time in both the urban and regional extents. Dongxihu, Caidian, Huangpi, and Jiangxia experienced accelerated growth and increasing AGRs. Consequently, fluctuating LPI and IJI metrics were observed at the regional scale over time, while SHDI varied for the different scales. Hannan showed a stable growth pattern represented by volatile AGR dynamics. The disorderly sprawl resulted in disparate LPI and SHDI at the urban and regional levels. Furthermore, the gradual growth pattern, which manifests in sustained growth shielded by a continuous decrease in AGR and diverse multi-scale landscape dynamics, is found in Xinzhou. Obviously, fluctuating growth is the most complicated pattern that can easily confound urban growth monitoring over time. These modes could be an efficient means for 
Table 6

Characteristics of growth patterns.

\begin{tabular}{|c|c|c|c|c|}
\hline Growth pattern & Sprawl rates & AGR dynamics & Landscape dynamics & Example \\
\hline Stable & Increasing at a stable speed & Fluctuates slightly & $\begin{array}{l}\text { Decreasing PD, LSI, SHDI and increasing } \\
\text { LPI independent of study scales }\end{array}$ & Hankou, Hanyang, Wuchang \\
\hline Accelerated & Increasing at a high speed & $\begin{array}{l}\text { Decreases slightly, } \\
\text { then increases sharply }\end{array}$ & $\begin{array}{l}\text { Oscillating LPI, IJI in regional areas; } \\
\text { disparate SHDI changes at multi-levels }\end{array}$ & $\begin{array}{l}\text { Dongxihu, Caidian, Huangpi, } \\
\text { Jiangxia }\end{array}$ \\
\hline Fluctuating & Increasing at fluctuating rates & Fluctuates sharply & Varied dynamics of LPI, SHDI a different scales & Hannan \\
\hline Gradual & Increasing slightly at low speeds & Decreases slightly & Varied dynamics of LPI, IJI, SHDI at different scales & Xinzhou \\
\hline
\end{tabular}

further urbanization measurements especially to determine the driving forces of sprawl (Uuemaa, Mander, \& Marja, 2013). However, the causative factors and influences of urbanization modes are complex. Migration, climate change, economic growth, and changing land use policies can induce diverse landscapes changes (Hersperger \& Bürgi, 2009; Zenou, 2011). Urbanization remains an international challenge for scholars and planners to understand the causative forces for spatial-temporal land-use changes at different scales (Buxton \& Taylor, 2011; Carley, Jenkins, \& Smith, 2001; Pôças, Cunha, \& Pereira, 2011). The introduced concise and cost-effective framework for UB identification is repeatable in similarly urbanizing areas and can contribute to periodic monitoring of multi-scale expansion process and their effects on the landscape.

\section{Conclusions}

This study provides a cost-effective and concise framework for extracting UBs from remotely-sensed imagery. The LUIE model for measuring local land-use diversity together with the framework for locating extreme LUIE pixels is suitable for frequent UB identification at large scales. Applications of UB identification in the years 1987, 1994, 2002 and 2010 in Wuhan, China indicate that the grid scale adopted for LUIE computation affected UB extraction by varying degrees. When the method was combined with ordinary Kriging, the OA of the identification reached 90\% in Hankou-Dongxihu, Hannan, and Huangpi. Furthermore, diverse landscapes were observed in different local administrative regions and city scale extents during the rapid urban sprawl that occurred in Wuhan. Further research will focus on empirical studies considering the possible influence of land use class types in different regions and the specific driving forces of urban sprawl at different scales. Carrying out replicable studies on UB extraction in different regions and characterizing urban growth modes at multiple scales will greatly aid in curbing excessive expansion, promoting naturalhuman development, and realizing appropriate neo-urbanization strategies in developing countries.

\section{Acknowledgements}

The authors would like to thank the anonymous reviewers and the editor, Dr. Charles L. Choguill, who provided constructive comments that greatly improved this article from its original form.This study was partly supported by grants from the National Science Foundation (No. 41101535 \& 41130748), China Postdoctoral Science Foundation (No. 2013M530709 \& 2014T70115), and Humanity and Social Science Youth foundation of Ministry of Education of China (No. 14YJCZH192). And thanks are also due to the Department of Land Resources, Hubei province for the supply of the land use map data.

\section{References}

Abed, J., \& Kaysi, I. (2003). Identifying urban boundaries: application of remote sensing and geographic information system technologies. Canadian Journal of Civil and Engineering, 30, 992-999.
Abedini, M., Nasseri, M., \& Ansari, A. (2008). Cluster-based ordinary kriging of piezometric head in West Texas/New Mexico - testing of hypothesis. Journal of Hydrology, 351, 360-367.

Aguilera, E., Valenzuela, L., \& Botequilha-Leitão, A. (2011). Landscape metrics in the analysis of urban land use patterns: a case study in a Spanish metropolitan area. Landscape and Urban Planning, 99, 226-238.

Amiri, R., Weng, Q., Alimohammadi, A., \& Alavipanah, S. (2009). Spatial-temporal dynamics of land surface temperature in relation to fractional vegetation cover and land use/cover in the Tabriz urban area, Iran. Remote Sensing of Environment, 113, 2606-2617.

Arribas-Bel, D., Nijkamp, P., \& Scholten, H. (2011). Multidimensional urban sprawl in Europe: a self-organizing map approach. Computers, Environment and Urban Systems, 35, 263-275.

Bai, X., Shi, P., \& Liu, Y. (2014). Society: realizing China's urban dream. Nature, 509 $158-160$.

Berger, C., Voltersen, M., Eckardt, R., Eberle, J., Heyer, T., Salepci, N., et al. (2013). Multi-modal and multi-temporal data fusion: outcome of the 2012 GRSS data fusion contest. IEEE Journal of Selected Topics in Applied Earth Observations and Research Sensing, 6, 1324-1340.

Bhatta, B., Saraswati, S., \& Bandyopadhyay, D. (2010). Urban sprawl measurement from remote sensing. Applied Geography, 30, 731-740.

Buxton, M., \& Taylor, E. (2011). Urban land supply, governance and the pricing of land. Urban Policy and Research, 29, 5-22.

Carley, M., Jenkins, P., \& Smith, H. (2001). Urban development and civil society: The role of communities in sustainable cities. London, UK: Earthscan.

CDRF. (2013). China's new urbanization strategy. Oxon: Routledge.

Chaudhry, O., \& Mackaness, W. (2008). Automatic identification of urban settlement boundaries for multiple representation databases. Computers, Environment and Urban Systems, 32, 95-109.

Chen, M., Liu, W., \& Tao, X. (2013). Evolution and assessment on China's urbanization 1960-2010: under-urbanization or over-urbanization? Habitat International, 38, 25-33.

Cheng, J., Turkstra, J., Peng, M., Du, N., \& Ho, P. (2006). Urban land administration and planning in China: opportunities and constraints of spatial data models. Land Use Policy, 23, 604-616.

Cockx, K. Voorde, T., \& Canters, F. (2014). Quantifying uncertainty in remote sensing-based urban land-use mapping. International Journal of Applied Earth Observation and Geoinformation, 31, 154-166.

Cohen, B. (2006). Urbanization in developing countries: current trends, future projections, and key challenges for sustainability. Technology in Society, 28 63-80.

Deng, J., Wang, K., Deng, Y., \& Qi, J. (2008). PCA-based land-use change detection and analysis using multitemporal and multisensory satellite data. International Journal of Remote Sensing, 29, 4823-4838.

Dhakal, S. (2009). Urban energy use and carbon emissions from cities in China and policy implications. Energy Policy, 37, 4208-4219.

Du, N., Ottens, H., \& Sliuzas, R. (2010). Spatial impact of urban expansion on surface water bodies - a case study of Wuhan, China. Landscape and Urban Planning, 94 $175-185$.

Elmqvist, T., Fragkias, M., Goodness, J., Güneralp, B., Marcotullio, P., McDonald, R. et al. (Eds.). (2013). Urbanization, biodiversity and ecosystem services: Challenges and opportunities. Springer.

Foody, G. (2000). Mapping land cover from remotely sensed data with a softened feedforward neural network classification. Journal of Intelligent and Robotic Systems, 29, 433-449.

Gaucherel, C. (2009). Self-similar land cover heterogeneity of temperature and tropical landscapes. Ecological Complexity, 6, 346-352.

Getis, A., \& Ord, J. (1992). The analysis of spatial association by use of distance statistics. Geographical Analysis, 24, 089-206.

Ghinire, B., Rogan, J., \& Miller, J. (2010). Contextual land-cover classification: incorporation spatial dependence in land-cover classification models using random forest and the Getis statistic. Remote Sensing Letters, 1, 45-54.

Han, H., Lai, S., Dang, A., Tian, Z., \& Wu, C. (2009). Effectiveness of urban construction boundaries in Beijing: an assessment. Journal of Zhejiang University Science A, 9, 1285-1295.

Haregeweyn, N., Fikadu, G., Tsunekawa, A., Tsubo, M., \& Meshesha, D. (2012). The dynamics of urban expansion and its impacts on land use/land cover change and small-scale farmers living near the urban fringe: a case study of Bahir Dar, Ethiopia. Landscape and Urban Planning, 106, 149-157.

Hermosilla, T., Palomar-Vázquez, J., Balaguer-Beser, Á., Balsa-Barreiro, J., \& Ruiz, L. (2014). Using street based metrics to characterize urban typologies. Computers, Environment and Urban Systems, 44, 68-79. 
Hersperger, A., \& Bürgi, M. (2009). Going beyond landscape change description: quantifying the importance of driving forces of landscape change in a Central Europe case study. Land Use Policy, 26, 640-648.

Hersperger, A., Franscini, M., \& Kübler, D. (2014). Actors, decisions and policy changes in local urbanization. European Planning Studies, 22, $1301-1319$.

Hollis, L. (2013). Cities are good for you: The genius of the metropolis. Bloomsbury Press.

Hu, S., Chen, Q., Wang, L., \& Xu, D. (2013). Modeling land price distribution using multifractal IDW interpolation and fractal filtering method. Landscape and Urban Planning, 110, 25-35.

Hu, S., \& Wang, L. (2013). Automated urban land-use classification with remote sensing. International Journal of Remote Sensing, 34, 790-803.

Hubacek, K., Guan, D., Barrett, J., \& Wiedmann, T. (2009). Environmental implications of urbanization and lifestyle change in China: ecological and water footprints. Journal of Cleaner Production, 17, 1241-1248.

Jafari, A., \& Babadagli, T. (2013). Relationship between percolation-fractal properties and permeability of 2-D fracture networks. International Journal of Rock Mechanics and Mining Sciences, 60, 353-362.

José-Ma, M., \& Beatriz, L. (2006). Estimating housing price: kriging the mean. International Advances in Economic Research, 12, 419.

Kane, K., Tuccillo, J., York, A., Gentile, L., \& Ouyang, Y. (2014). A spatio-temporal view of historical growth in Phoenix, Arizona, USA. Landscape and Urban Planning, $121,70-80$.

Knight, J. (2013). The economic causes and consequences of social instability in China. China Economic Review, 25, 17-26.

Krige, D. (1951). A statistical approach to some basic mine valuation problems on the Witwatersrand. Journal of the Chemical, Metallurgical and Mining Society of South Africa, 52, 119-139.

Lausch, A., \& Herzog, F. (2002). Applicability of landscape metrics for the monitoring of landscape change: issues of scale, resolution and interpretability. Ecological Indicators, 2, 3-15.

Lin, Y., \& Bao, K. (2005). The impact of the scan lines corrector malfunction on Landsat-7 imagery data and the processing methods. Remote Sensing Information, 2, 33-35 (in Chinese with English abstract).

Lopez, E., Bocco, G., Mendoza, M., \& Duhau, E. (2001). Predicting land-cover and land-use change in the urban fringe: a case in Morelia city, Mexico. Landscape and Urban Planning, 55, 271-285.

Mairota, P., Cafarelli, B., Labadessa, R., Lovergine, F., Tarantino, C., Nagendra, H., et al. (2015). Very high resolution earth observation features for testing the direct and indirect effects on landscape structure on local habitat quality. Internationa Journal of Applied Earth Observation and Geoinformation, 34, 96-102.

Mandelbrot, B. (1967). How long is the coast of Britain? Science, 156, 636-638.

Mantheron, G. (1963). Principles of geostatistics. Economic Geology, 58, 1246-1266.

McGarigal, K., \& Marks, B. (1995). FRAGSTATS: Spatial pattern analysis program for quantifying landscape structure. Portland, Oregon: U.S. Department Of Agriculture, Forest Service, Pacific Northwest Research Station.

Mohan, M., Pathan, S., Narendrareddy, K., Kandya, A., \& Pandey, S. (2011). Dynamics of urbanization and its impact on land use/land cover: a case study of Megacity Delhi. Journal of Environmental Protection, 2, 1274-1283.

Morelli, F., Pruscini, F., Santolini, R., \& Perna, P. (2013). Landscape heterogeneity metrics as indicators of bird diversity: determining the optimal spatial scales in different landscapes. Ecological Indicators, 34, 372-379.

Mulligan, G. (2013). Revisiting the urbanization curve. Cities, 32, 113-122.

National Bureau of Statistics. (2013). Statistical yearbooks of China. Beijing: China Statistics Press.

Oizumi, K. (2011). The emergence of the Pearl River Delta economic zone. RIM: Pacific Business and Industries, 11, 2-20.

Pacifici, F., Chini, M., \& Emery, W. (2009). A neural network approach using multiscale texture metrics from very high resolution panchromatic imagery for urban land-use classification. Remote Sensing of Environment, 113, 1276-1292.

Pal, M., \& Foody, G. (2010). Feature selection for classification of hyperspectral dat by SVM. IEEE Transactions on Geoscience and Remote Sensing, 48, 2297-2307.
Patino, J., \& Duque, J. (2013). A review of regional science applications of satellite remote sensing in urban settings. Computers, Environment and Urban Systems, $37,1-17$.

Plexida, S., Sfougaris, A., Ispikoudis, I., \& Papanastasis, v. (2014). Selecting landscape metrics as indicators of spatial heterogeneity - a comparison among Greek landscapes. International Journal of Applied Earth Observation and Geoinformation, 26, 26-35.

Pôças, I., Cunha, M., \& Pereira, L. (2011). Remote sensing based indicators of changes in a mountain rural landscape of northeast Portugal. Applied Geography, 31, $871-880$.

Richards, J. (2013). Remote sensing digital image analysis. Heidelberg: SpringerVerlag.

Rocchini, D., Foody, G. M., Nagendra, H., Ricotta, C., Anand, M., He, K. S., et al. (2012). Uncertainty in ecosystem mapping by remote sensing. Computers \& Geosciences. http://dx.doi.org/10.1016/j.cageo.2012.05.022.

Schneider, A., Friedl, M., \& Potere, D. (2014). Mapping global urban areas using MODIS 500-m data: new methods and datasets based on 'urban ecoregions' Remote Sensing of Environment, 114, 1733-1746.

Schneider, A., \& Woodcock, C. (2008). Compact, dispersed, fragmented, extensive? A comparison of urban growth in twenty-five global cities using remotely sensed data, pattern metrics and census information. Urban Studies, 45, 659-692.

Shannon, C. (1949). The mathematical theory of communication. Urbana: University of Illinois Press.

Siciliano, G. (2012). Urbanization strategies, rural development and land use changes in China: a multiple-level integrated assessment. Land Use Policy, 29, 165-178.

Soergel, U. (Ed.). (2010). Radar remote sensing of urban areas. Heidelberg: Springer.

Tannier, C., \& Thomas, I. (2013). Defining and characterizing urban boundaries: a fractal analysis of theoretical cities and Belgian cities. Computers, Environment and Urban Systems, 41, 234-248.

Tannier, C., Thomas, I., Vuidel, G., \& Frankhauser, F. (2011). A fractal approach to identifying urban boundaries. Geographical Analysis, 43, 211-227.

Taubenböck, H., Wiesner, M., Felbier, A., Marconcini, M., Esch, T., \& Dech, S. (2014). New dimensions of urban landscapes: the spatio-temporal evolution from a polynuclei area to a mega-region based on remote sensing data. Applied Geography, 47, 137-153.

Tian, G., Qi, Z., \& Zhang, Y. (2012). The investigation of relationship between rural settlement density, size, spatial distribution and its geophysical parameters of China using Landsat TM images. Ecological Modelling, 231, 25-36.

United Nations, Department of Economic and Social Affairs, Population Division. (2012). World urbanization prospects: The 2011 revision. CD-ROM Edition - Data in digital form (POP/DB/WUP/Rev.2011).

Uuemaa, E., Mander, Ü., \& Marja, R. (2013). Trends in the use of landscape spatial metrics as landscape indicators: a review. Ecological Indicators, 28, 100-106.

Valbuena, D., Verburg, R., Bregt, A., \& Lightenberg, A. (2010). An agent-based approach to model land-use change at a regional scale. Landscape Ecology, 25, 185-199.

Valeriano, M., Kuplich, T., Storino, M., Amaral, B., Mendes, J., \& Lima, D. (2006) Modeling small watersheds in Brazilian Amazonia with shuttle radar topographic mission-90 m data. Computers \& Geosciences, 32, 1169-1181.

Weber, C. (2001). Remote sensing data used for urban agglomeration delimitation. In J. P. Donnay, M. J. Barnsley, \& P. A. Longley (Eds.), Remote sensing and urban analysis (pp. 155-167). London: Taylor and Francis.

Weber, C., \& Puissant, A. (2003). Urbanization pressure and modeling of urban growth: example of the Tunis Metropolitan Area. Remote Sensing of Environment, 86, 341-352.

Wu, S., Qiu, X., Usery, E., \& Wang, L. (2009). Using geometrical, textural, and contextual information of land parcels for classification of detailed urban land use. Annals of the Association of American Geographers, 99, 76-98.

Wuhan Municipal Statistics Bureau. (2013). Wuhan statistical yearbook-2013. Beijing: China Statistics Press.

Zenou, Y. (2011). Search, migration, and urban land use: the case of transportation policies. Journal of Development Economics, 96, 174-187. 